Pakistan Journal of Humanities and Social Sciences
Volume 8, Number 1, 2020, Pages 15 - 22

\title{
Impact of Trade Openness on Industrialization in Nigeria
}

\author{
Adebayo Mohammed Ojuolape ${ }^{1}$, Deborah Boluwatife Adeniyi², Nusirat Ojuolape Gold ${ }^{3}$, \\ Ayodele Folorunso Oshodi ${ }^{4}$ \\ ${ }^{1}$ Economics Program, School of Social Sciences, Universiti Sains Malaysia (USM) and Department of Economics, \\ University of Ilorin, Nigeria Email: ojuolape.ma@unilorin.edu.ng \\ ${ }^{2}$ Department of Economics, University of Ilorin, Nigeria, Email: Adeniyi.deborah@outlook.com \\ ${ }^{3}$ Department of Accounting, Kwara State University, Malete, Nigeria \\ ${ }^{4}$ Department of Economics, University of Ilorin, Nigeria.
}

ARTICLE I NFO

\section{Article History:}

Received: February 16, 2020

Revised: $\quad$ March 18, 2020

Accepted: $\quad$ March 24, 2020

Available Online: March 31, 2020

\section{Keywords:}

Trade openness

Industrialization

Nigeria

\section{JEL Classification Codes: P45, L69}

\section{A B S T R A C T}

The state of Nigeria as regards the effect of trade openness on industrialization is a major concern. This research helps to evaluate this effect. The variables show a long-run relationship, using the Bound Cointegration test. The final analytical result was gotten using ARDL (Auto-Regressive Distributed Lag) Co-integration and Long-run form. The results show that trade openness is not significant, and it is negatively related to industrialization. The implication of this is that it hinders industrialization in Nigeria. This is due to excess importation and infrastructure deficit, alongside other factors. The study recommended that existing policies should not be waved aside; there should be engaged in international industrial competitiveness and stabilization of the exchange rate.

(c) 2020 The Authors, Published by iRASD. This is an Open Access Article under the Creative Common Attribution Non-Commercial 4.0

Corresponding Author's Email: ojuolape.ma@unilorin.edu.ng

\section{Introduction}

Industrialization is the engine of growth of an economy and a prerequisite for take-off on economic development by any country. It is, therefore, necessary to look into factors that aid its growth, such as trade openness (Jhingan, 2012). Trade of a nation is one of the critical determinants for the improvement of industrialization in developing countries. Trade openness increases the growth of export-oriented industries and the importation of necessary primary and capital goods required for the completion of production. Hence, there can be an enhancement in technology acquisition through trade openness (Okoye, Nwakoby \& Okorie, 2016). Different policies have been carried out on the openness of trade in Nigeria, either by reducing or decreasing it to help improve the state of industrialization but most to no avail. This study compares the past to the present, as there were effects of trade policies on industrialization in the past. Hence; showing effective measures or policies that are being neglected. This study seeks to answer the questions below;

- Does trade openness help or hinders industrialization in Nigeria?

- Is there any long-run relationship between trade openness and industrialization in Nigeria?

This study covers the relationships between trade openness and industrialization and their particular importance to the Nigerian economy. The research work analyzed how trade openness affects industrialization in Nigeria. This research uses the ARDL (Auto-Regressive Distributed lag) Co-integrating and Long-run Form regression technique, to test the time series data from 1981-2016, which helped derive policy issues according to the result given. Two other variables (Exchange and Inflation rates) were included to make the model fit for estimation. The period is essential as it captures most policy reforms and response in the industrial sector over time. 
It is expected that the analytical results and proffered from this research would be of advantage to policymakers, to make the right trade policies that will make trade openness favor industrialization in Nigeria. Investors will also benefit from this study, as it will make them know the merits and demerits of trade openness, thereby helping them to make appropriate decisions on investment.

\section{Literature Review \\ 2.1 Conceptual Framework}

Trade is the exchange of goods and/or services, given a market platform. An open economy generally, is the one that allows for import and export. Openness is the degree of liberation of an economy to importation and exportation of goods and services (Hardison, 2009). The concept of industrialization can be interpreted from a narrow and broad sense, and it concerns structure and efficiency. It is a process by which a country transforms from a less mechanized economy to a more technologically advanced one. Individual labor is often replaced by mechanization. It enhances the use of productive inputs, by giving a range of available technologies, better structures, and a suitable environment for mass production (sufficient for national consumption) of quality goods. It also enhances the exportation of excesses (Ekpo, 2005).

\subsection{Overview of Trade Openness and Industrialization in Nigeria}

Industries were majorly craft industries in the pre-independence era (1943-1959). These industries were overtaken by raw material processing industries, for the benefit of the colonial rulers, which made the exportation of raw materials to their country easier. Here, trade openness, as a result of the imperial government, made the country neglect the primary craft industries and faced solely raw material processing industries. Although this was a form of exploitation, it added to the growth of industries in a decreasing way, because the primary industry was neglected (Dagogo, 2014).

In the post-colonial era (1960-1969), the country set out to make the economy an industrial one, with a high priority on rapid growth, as contained in the objectives of the First National Development Plan (1962-1968). The economy was made less opened; to increase production and consumption of locally made goods, since importation was getting higher than exportation. The establishment of these industries was with low capacity technologies, and major plants were imported, making it difficult to manage and maintain (Dagogo, 2014).

Under the Second National Development Plan 1970-1974 in the oil boom era (the 1970s), the focus of industrial development was to encourage balanced growth and fair distribution of industries, quick development, and diversification of the industrial sector. This aim of these was to increase incomes from manufacturing, reduce unemployment, and encourage the erection of large industries in strategic sectors, to proceed with the program of import-substitution, to kick start local labor schemes in industries, and to increase the level of local ownership of industrial investment (Federal Ministry of Information, 1970).

\subsection{Theoretical Review}

Generally, there is an assertion that trading nations will enjoy better economic growth than closed economies. Many studies have been carried out which justifies this finding, although there has been no firm conclusion (Hardison, 2009). Adam Smith and David Ricardo gave the classical theories of international trade. To them, an open economy enjoys specialization, efficient allocation of resources; introduces new technical ideas. The classical theories are divided into three theories as follows;

\subsubsection{Mercantilism Theory}

This theory promotes export, but it is against imports. It sees export as gain and import as loss, thereby stating that national wealth is a function of the difference between import and export, and restrictive measures such as tariffs, embargo, etc. should be placed on import goods (Smith, 1976).

\subsubsection{Theory of Absolute Advantage}

A country should import goods and services that will cost more if produced locally, but produce and export goods and services that cost less. When a country can make a product at a 
higher quality and faster rate, it should produce and export, but import if otherwise (Smith, 1976).

\subsubsection{Theory of Comparative Advantage}

David Ricardo propounded this theory. Comparative advantage is the opportunity cost of a nation producing a particular good. Goods with lower opportunity costs are produced and exported, thereby managing efficiently limited resources available in the country. Therefore, goods with higher opportunity costs are better imported. The foreign exchange gap cannot be reduced by the importation of foreign capital from industrialized nations since the reduction in prices of developing countries on the primary commodity is not offset by the increasing prices of goods from industrialized countries (Rweyemamu, 1992).

\subsubsection{Posner's Imitation Gap or Technological Gap Theory}

Ricardian and Heckscher-Ohlin assumed that there is the same technology for all open economies. Kravis disagreed with this assumption and came up with the effect of technical change on exports. Posner (1961) contributed to his theory and examined the impact of technology on trade. Therefore he came up with the imitation gap. This theory explains the effect of imitation and innovation on trade patterns. The exporting country first innovates its technology for domestic trade and later expands by selling to the other country, having an absolute advantage in the product. Imitation is then encouraged in the importing country when the exporting country must have had a high profit. Till the country importing starts to produce the product, the exporting country will continue to have a comparative advantage in its production.

He introduced a concept called 'Dynamism', emanating from the composition of innovation and imitation lag. Posner further affirms that there will be no balance of payment difficulties for these countries if they have an equal degree of dynamism; otherwise, there will be competitiveness and a further increase in technical progress and product improvement (Ellsworth \& Clark, 1975). A crucial factor that affects openness of trade is the "trade barrier." This gives less freedom of choice of goods. Therefore industries may have to make do with what is available (usually inferior inputs compared to the ones that could have been imported). These barriers are designed to keep out foreign firms (Busch \& Pelc, 1997).

All nations cannot benefit from trade openness as long as there are disparities in responsiveness to growth, and benefits depend on so many endogenous factors. Each nation needs to have its specialty, but this also depends on the macroeconomic stability (Guerrieri, 2006). Industrialization plays a key role in the economic development of underdeveloped countries. The developed nations broke their vicious circle of poverty by industrialization, rather than focusing on the production of national resources. This cannot be achieved by a nation being independent of others. There is a need for many ideas, quality assistance from other countries to start with, and then, less can be needed as the nation becomes developed. Nevertheless, even developed countries are seen to have a greater dependence than developing countries (Saif, 2017).

\subsection{Empirical Literature}

From a research carried out by Maria (2004), who made use of Ordinary Least Square regression techniques, data were gotten on Gross Domestic Product (GDP), which served as a proxy for economic growth. There was also data on import and export duties, which were proxy for the tariff. Tariff barrier, aggregate export, and openness showed a positive relationship with economic growth, while aggregate import and ratio of export to GDP did not. The conclusion was that trade barriers have a positive and significant effect on Nigeria's economic growth.

A Study on Linkages between Trade Openness, Productivity, and Industrialization in Nigeria employed the Vector Autoregressive (VAR) analysis, to examine the impact of trade openness and total factor productivity on industrial output. The conclusion was that trade openness is essential for the growth of industries (Adofu \& Innocent, 2017). Hardison (2009) used large open measures for a cross-section of countries for over thirty years. His result showed that trade barriers are positively and significantly related to growth. Ebong, Udo, and Obafemi (2014) made use of Engel-Granger; two-step, and Johansen cointegration tests. The vector autoregressions technique was used with error correction to examine the effect of 
international trade on the industrial development of Nigeria. His result was positive; therefore, it is of great advantage to enhance the level of trade. From the theoretical and empirical review above, it is evident that trade openness is crucial for industrial growth in economies. However, few studies pointed out some of its adverse effects on industrial growth. Moderate measures should then be taken to address this issue.

\section{Research Methodology}

\subsection{Theoretical Framework}

The Posner's Imitation Gap or Technological Gap Theory is singled out by the researcher, among other international trade theories as stated in chapter two, because it is the most suitable theory for this research, according to the researcher's knowledge. Trade openness gives more room for improvement of industrial technology when an importing country begins to imitate an exporting country's new product. This will help increase the technical efficiency of industries, thereby helping the country to produce by itself and even sell to other countries. It also reduces difficulties in attaining a balance of payment equilibrium. The imitation gap theory seems to be more realistic than the traditional theories because it analyses the effect of technology on the pattern of trade.

\subsection{Model Specification}

An econometric model was adopted in this research, based on its adoption in most studies reviewed in chapter two. It contains the evaluation technique, which is the multiple regression analysis, showing the relationship between the dependent and independent variables. The model is derived from Posner's imitation theory (1961), that trade openness increases the tendency of technical and production progress in trading countries. More independent variables were added to make the model a good fit. The dependent variable is the industrial output (IDO), as a proxy for industrialization, while independent variables are the openness index (TPG), an exchange rate (EXR), and inflation rate (INR). $U$ is the error term. These are illustrated econometrically as;

$$
I_{D}=\beta_{0}+\beta_{1} T P G_{t}+\beta_{2} E X R_{t}+\beta_{3} I N R_{t}+U_{t} .
$$

\subsection{Nature and sources of data}

It is essential that quantitative data, that is, measurable data be used for the success of this study. The source of data is secondary, gotten from WDI (World Development Indicators) and Central Bank Statistical Bulletin, from 1981 to 2016.

\subsection{Estimation Technique}

\subsubsection{Descriptive Statistics}

Descriptive statistics were used to summarize the data. It includes measurements such as the mean, standard deviation, skewness, and other descriptive components.

\subsubsection{Unit Root Test (Augmented Dickey-Fuller Test)}

This test is used to examine the property of the variables. It is used to test for the nonstationarity of variables to make them stationary.

\subsubsection{Bound Co-integration Test}

A bound cointegration test is an estimation tool to check the long-run relationship among variables. It provided the answer to the second research question. It is a more suitable cointegration test for this study because series are integrated in order of zero and one.

\subsubsection{ARDL Co-integrating and Long-run Form}

This is the initial estimation that helped to answer the research question. This was employed to estimate the model. Some post estimations were also carried out to confirm the regression result such as the Breusch-Godfrey serial correlation test, heteroskedasticity test, and histogram normality test.

\section{Presentation and Analysis of Results \\ 4.1 Descriptive Statistics}

Table 1 is a summary of the descriptive statistics. This shows that the average trade percentage of GDP and industrial output, from 1981 to 2016 in Nigeria are 50.90815 and 
9.102146, respectively. The average value of the exchange rate and inflation rate are 76.59229 and 19.60305 , respectively. The values over the years range from the lowest to the highest value of 9.531789 and 8.568814 for industrial output, 81.81285 and 21.12435 for trade, 253.4900, and 0.610025 for the exchange rate, and 72.83550 and 5.382224 for inflation rate respectively.

Table 1: Summary of Descriptive Statistics

\begin{tabular}{lllll}
\hline & LIDO & TPG & EXR & INR \\
\hline Mean & 9.102146 & 50.90815 & 76.59229 & 19.60305 \\
Median & 9.053305 & 52.91216 & 57.37000 & 12.54679 \\
Std. Dev. & 0.275974 & 16.41159 & 72.03789 & 17.69043 \\
Skewness & -0.133343 & -0.196806 & 0.423718 & 1.664533 \\
Kurtosis & 1.881931 & 2.103368 & 1.985539 & 4.526585 \\
\hline
\end{tabular}

Source: E-views 9

The standard deviation shows how far the variables spread from the mean; and the lower the deviation from the mean, the better the representation of variables. The standard deviation of industrial output, which is 0.275974 , implies that there is little deviation from the mean; while that of trade which is 16.41159 implies that there is a moderate deviation from the mean. The standard deviation of 72.03789 for the exchange rate shows that there is a far deviation from the mean; while that of the inflation rate which is 17.69043 has a moderate deviation from the mean.

Skewness is to check for the lack of symmetry. Distribution is symmetric if it has equal half or if it equals zero. If the skewness is more significant than 1 or less than 1 , the skewness is substantial, and the distribution is far from symmetrical. The skewness for the industrial output, which is -0.133343 , is lesser than 1 . Therefore, the variable's distribution is far from being symmetric. The skewness of the trade percentage of GDP is -0.196806 . This is also lesser than 1; therefore, the distribution is far from symmetrical. The exchange rate's skewness is 0.423718 , which is higher than 1 . Therefore the distribution is not symmetrical. The skewness of the inflation rate is 1.664533. This is also higher than 1 ; therefore, the distribution is not symmetric. All kurtosis values in the descriptive statistic are positive. This implies that there is a presence of outliers in the variables.

\subsection{Presentation of Estimated Model}

Table 2 shows that all variables are stationary at first difference except the inflation rate (INR) which is stationary at level.

Table 2: Unit Root Test for stationarity - summary of ADF test results

\begin{tabular}{lccccccc}
\hline & At level & \multicolumn{5}{c}{ At first difference } \\
& T-stat & Prob & Remarks & T-stat & Prob & Remarks & O I \\
\hline LIDO & -3.226062 & 0.0959 & Not Stationary & -5.009257 & 0.0015 & Stationary & I(1) \\
TPG & -1.916107 & 0.3213 & Not Stationary & -7.999128 & 0.0000 & Stationary & I(1) \\
EXR & $-\mathrm{I} .916729$ & 0.6246 & Not Stationary & -4.017358 & 0.0175 & Stationary & I(1) \\
INR & -3.836192 & 0.0266 & Stationary & & & & I(0) \\
\hline
\end{tabular}

Source: Author's compilation, Decision rule: If the P-value is greater than a $5 \%$ level of significance, we do not reject $\mathrm{Ho}$, but if the $P$-value is lesser than the $5 \%$ level of significance, we reject $\mathrm{Ho}$.

\subsubsection{Bound Test for the Existence of co-integration}

The F-statistic from the above (6.564149) is greater than the critical values for the upper bound I (1) and not lesser than the lower bound. Therefore we reject the null hypothesis and conclude that there is co-integration or long-run relationship between the dependent and independent variables. This implies convergence in the long-run among variables LIDO, TPG, EXR, and INR.

Table 4 shows the sign, significance, and size of each variable. The sign (+ or -$)$ shows if there is a positive or negative relationship, respectively. An increase in the trade percentage of GDP reduces industrial output by its coefficient $(-0.000629)$. Both the exchange rate and the inflation rate have positive relationships with the dependent variable (industrial output). The size is the magnitude of the impact of an independent variable on the dependent variable, where the coefficients are the magnitudes. That is, an increase in each of these independent 
variables will cause the industrial output to increase by their coefficients. The R-squared ( 0.833307$)$ indicates that the model is of good fit because $R$-squared measures the goodness of fit of a model from the range of 1 to 0.0 .83307 is closer to 1 ; therefore it implies the model has a good fit.

Table 3: Null Hypothesis: No long-run relationships exist

\begin{tabular}{lccc}
\hline Variables & Significant & $\mathrm{I}(0)$ Bound & $\mathrm{I}(1)$ Bound \\
\hline LIDO & $10 \%$ & 3.47 & 4.45 \\
TPG & $5 \%$ & 4.01 & 5.07 \\
EXR & $2.5 \%$ & 4.52 & 5.62 \\
INR & $1 \%$ & 5.17 & 6.36 \\
\hline
\end{tabular}

Source: Author's compilation, Decision Rule: If the F-statistic is higher than the critical value for the upper bound I (1), then there is co-integration or long-run relationship. If it is lesser than the lower bound, then there is no cointegration.

Table 4: ARDL Co-integrating and Long-run Form

\begin{tabular}{lcccc}
\hline Variable & Coefficient & Std. Error & T-statistics & Prob. \\
\hline TPG & -0.000629 & 0.002022 & -0.311015 & 0.7604 \\
EXR & 0.004671 & 0.000510 & 9.160745 & 0.0000 \\
INR & 0.005625 & 0.002446 & 2.299818 & 0.0374 \\
C & 8.753879 & 0.096593 & 90.626432 & 0.0000 \\
\hline R-squared & 0.833307 & & Mean dependent var. & 0.020547 \\
Adjusted R-squared & 0.545383 & & S.D. dependent var. & 0.062477 \\
S.E. of Regression & 0.042126 & & Sum squared resid. & 0.019520 \\
Durbin-Watson stat & 1.202871 & & Long-run Variance & 0.037454 \\
\hline
\end{tabular}

Source: Author's compilation

\subsubsection{Hypotheses Testing}

$\mathrm{H}_{0}$ : Trade openness does not have a positive and significant impact on industrialization in Nigeria.

$\mathrm{H}_{1}$ : Trade openness has a positive and significant impact on industrialization in Nigeria.

The decision rule is to reject $\mathrm{H}_{0}$ when the probability value is lesser than a $5 \%$ level of significance, but not rejecting $\mathrm{H}_{0}$ when the probability value is greater than the $5 \%$ level of significance.

\subsubsection{Histogram-Normality Test}

The histogram-normality test shows that the model is normally distributed and therefore correctly specified, or that there is a linear relationship between the dependent and independent variables since the probability $(0.381000)$ is greater than a $5 \%$ level of significance.

\subsubsection{Breusch-Godfrey Serial Correlation Test}

The serial correlation LM test shows that there is no serial correlation among the variables, that is, there is the randomness of explanatory variables since the $p$-values $(0.6318$ and 0.1862 ) are greater than the $5 \%$ level of significance.

\subsubsection{Heteroskedasticity Test}

The Heteroscedasticity test shows that there is no wide variance in the model since the p-values ( 0.6317 and 0.5216$)$ are greater than the $5 \%$ level of significance.

\section{Policy Issues}

The regression result shows that the trade percentage of GDP in Nigeria does not favor industrial output since there is usually much consumption of foreign products (importation), which reduces the productivity of domestic Industries. Producers will not want to have inventories; therefore, they produce the number of goods estimated to meet demand. Since demand is low, the quantity supply will also reduce. This most especially affects the infant industries, although policy measures are being taken for their protection, there are usually problems in implementing them (a major problem is corruption). The other macroeconomic variables (the exchange rate and inflation rate) are significant and positively related to industrial output because their increase reduces the rate at which goods are imported. Since 
the domestic value of money is now low, which means that there are fewer goods the domestic currency can buy abroad, this will make consumers resort to local goods, thereby increasing industrial output.

\section{Conclusion and Recommendations}

This study pointed out the relationship between trade openness and industrialization in Nigeria, specifically on the effect of the former on the latter. Many scholars have looked into this in different countries and made their points, for which most results turned out to be positive. In this study, the result gotten from the regression in chapter four, using ARDL Cointegrating and Long-run Form, showed that trade openness has a negative relationship with industrialization in Nigeria. The model used was based on Posner's imitation theory, but other important variables were added, such as exchange rate and inflation rate. Data were sourced from Central Bank Statistical Bulletin and WDI (World Development Indicators), using time series data of 36 years, spanning from 1981 to 2016. Although trade openness is negatively related to industrialization in Nigeria, the bound test result shows that they have a long-run relationship.

Based on the data analysis, we can conclude that trade openness hinders industrialization in Nigeria. Also, the relationship between the two macroeconomic variables is not significant. The fact that trade openness compensates for the growth of industries in some other countries does not guarantee the same for Nigeria. Nigeria's economy seems to be abnormal because of its various hindrances to industrial growth, such as infrastructural deficit and unstable macroeconomic policies, among others. Based on Posner's imitation theory, Nigeria rarely imitates imported products. Imitation lag usually takes an extended period, which means there will be a continuous importation of a new product until the importing country can fully imitate it. Little or no imitation of the product will cause a further increase in the importation of such products, which is exactly the situation Nigeria has found itself. This is because consumers prefer to buy original products.

Based on the above findings and conclusions, the following are the suggested recommendations to enhance industrialization in Nigeria:

- The effect of trade openness on industrialization is not significant and is negative, based on the regression result. This is because there is usually too much of importation of goods and services, thereby making the country a dumping ground. Therefore, importation should be restricted to make the relationship between trade openness and industrialization significant and positive.

- New administrations usually present new policies without referring to the policies of the past administration. Present and subsequent administrations should continue with existing policies to ensure the effective implementation of these policies.

- Based on Posner's imitation theory, there will be no balance of trade difficulties for Nigeria if the country has equal dynamism with countries she is trading with. Although this may not be possible, because when the dynamism of one country is more than the other, it creates competitiveness, better techniques, and better products. Therefore the economy's dynamism might not necessarily equal other countries, but it should strive not to lag in its dynamism. Ensuring proper maintenance of industrial infrastructural facilities should also be taken into consideration.

- The exchange rate should be regulated and stabilized to encourage export. The volatility of the exchange rate gives investors less assurance of profitable investment. If the exchange rate is stabilized and regulated as it should be, investors will be more confident to go into more production of goods and services.

- According to the researcher's findings, developed countries form cartels, which makes a trade with the developing countries more favorable to them, at the expense of the developing countries. The developing countries should also form cartels, which will make negotiations with developed countries favorable to them, as a group of countries will have more power than an individual country. 


\section{References}

Adofu, I., \& Innocent, O. (2017). Linkages between trade openness, productivity, and industrialization in Nigeria: a co-integration test. Research in World Economy, 8(2), 7981.

Busch, M. L., \& Pelc, K. J. (1997). Law, politics, and the true cost of protectionism: The choice of trade remedies or binding overhang. World Trade Review, 2014, 13(1), 39-64.

Dagogo, W. D. (2014). Nigerian industrial development between 1943 and 2013: challenges and opportunities. International Review of Research in Emerging Markets and the Global Economy (IRREM); An Online International Review of Social Sciences and Humanities, $6(2), 12-24$

Ekpo. (2005). The Challenges of Industrialization: A pathway of Nigeria becoming a highly industrialized country in the year 2015. Ibadan: Nigeria Economic Society Press.

Federal Ministry of Information. (1970). Second National Development Plan 1970-1974. Lagos: Government Printer.

Guerrieri, L. (2006). The inflation persistence of staggered contracts. Journal of Money, Credit and Banking, 38(2), 483-494.

Hardison, P. L. (2009, June 4). "What is trade openness, and what is the effect of trade openness on economic/financial development? Retrieved from https://www.enotes.com/homework-hlp/what-trade-openness-87695

Jhingan, M. (2012). The economics of development and planning $40^{\text {th }}$ edition. India: Delhi Vrinda Publications.

Maria, D. W. (2004). Empirical analysis of trade barriers and economic growth of Nigeria. Article in European Journal of Social Sciences, 2(4), 1-6.

Okoye, L. U., Nwakoby, I. N., \& Okorie, E. U. (2016). Economic openness and industrial development in Nigeria. Journal of Policy and Development Studies, 10(1), 12-16.

Posner, M. V. (1961). International trade and technical change. Oxford Economic Papers, $13(3), 323-341$

Rweyemamu, J. F. (1992). Dialogue for a New Order; Third World Options: Power, security, and hope for another development. Tanzania: Tanzania Publishing House.

Saif, S. A. (2017). The Impact of Trade Openness on Per Capital Income in Kuwait: Asian Economic and Social Society, 7(5), 448-455.

Smith, A. (1976). An Inquiry into the Nature and Causes of Wealth of Nations (3rd ed.). Oxford: Clarendon Press. 